Research, part of a Special Feature on Landscape Scenarios and Multifunctionality - Making Land Use Assessment Operational

\title{
The Use of Impact Assessment Tools to Support Sustainable Policy Objectives in Europe
}

\author{
$\underline{\text { Peter De Smedt }}^{1}$
}

\begin{abstract}
Sustainable development has become an overall policy objective in Europe. The sustainability transition is seen as the process of coming to terms with sustainability in all its ecological, social, economic, and institutional dimensions. This challenging process is as much about new ways of knowing as it is about resource management and product innovation. I analyzed how scientific tools such as environmental, socioeconomic, and integrated models have been developed and used to provide a solid foundation for sustainable policy objectives. I used a scoping study to compare current impact assessment exercises and research policy cases within the European Commission (EC). Although the EC is recognized as having supported environmental policy integration for more than three decades, updated insight is relevant because the current impact assessment system within the EC is highly dynamic, involving frequent new policy commitments and institutional initiatives to strengthen its practice and quality within the last three years. In addition, a broad range of research projects have been initiated to support this process by developing new concepts and tools and linking them with actual policy initiatives. Finally, the focus on design and use of scientific tools will contribute to a better understanding of what hinders the tools from being relevant, accurate, and legitimate. For example, while being simplifications of reality, many scientific models remain so complex that they are seen as black boxes instead of transparent analytical tools. Consequently, research outcomes do not fully reach policy makers.
\end{abstract}

Key Words: impact assessment; science-policy interface; sustainability

\section{INTRODUCTION}

\section{Impact assessment system}

In 2003, the impact assessment (IA) system was introduced in the European Commission (EC), replacing and integrating all sectoral assessments of direct and indirect effects of proposed measures into one global, integrated instrument. This system was announced in the communication on impact assessment (European Commission 2002) in which the commission commits to improve the quality and coherence of the policy development process, to contribute to an effective and efficient regulatory environment, and to implement a more coherent European strategy for sustainable development. That document explains how the process of IA will be implemented gradually in the EC for all major initiatives, i.e., those presented in the EC's work program (European Commission 2002).

IA is designed to be a process that prepares, for political decision makers, evidence on the advantages and disadvantages of possible policy options by assessing their potential effects. The IA system is structured by a common set of basic questions, minimum analytical standards, and a common reporting format (European Commission 2002). IA is part of the policy formulation stage; the results of the process are summarized and presented in an IA report. For reasons of simplification, IA was chosen as the overall concept (Ruddy and Hilty 2008). However, integration is foreseen as an essential element of the IA system. These new IA procedures, including official IA guidelines, became fully operational in 2005 (Lee and Kirkpatrick 2006). The IA system is implemented 
as a decentralized approach whereby each service organization is responsible for preparing the IA hand-in-hand with the related policies. The lead service organization responsible for preparing the policy is also responsible for doing the IA, including stakeholder consultations. The results and conclusions of the impacts evaluated by all IAs are integrated by the lead service organization into the policy-making process, thereby guiding final policy decisions by anticipating the possible effects of the proposed policy. However, IA is an aid, not a substitute, for political judgment (European Commission 2002).

The current IA system within the EC is highly dynamic and has involved frequent new policy commitments and institutional initiatives to strengthen its practice and quality over the last three years. Two examples of relevant policy commitments are the renewed sustainable development strategy (renewed EU SDS) and the Seventh Framework Programme for Research (FP7). The overall aim of the renewed EU SDS is to identify and develop actions to enable the EU to achieve continuous improvement of quality of life, both for current and future generations, through the creation of sustainable communities that are able both to manage and use resources efficiently and to tap the ecological and social innovation potentials of the economy, ensuring prosperity, environmental protection, and social cohesion (Council of the European Union 2006a). To fulfill this ambitious obligation, the EC has committed to evaluate the impacts that all new policies have within and outside the EU as part of the IA system (Adelle et al. 2006). The key challenges of the renewed EU SDS are mirrored in FP7, highlighting the important role of research in supporting the development of sustainable policy objectives. FP7 is the EU's main instrument for funding research and supports collaborative European research projects. More specifically, FP7 supports the development and use of scientific tools to quantitatively assess the environmental and research policy contributions to sustainable development, including assessments of market-based and regulatory approaches, as well as the effects of current trends in production and consumption patterns. Such tools include models that consider the links among economy, environment, and society (Council of the European Union 2006b).

In 2005, the EC published IA guidelines for assessing potential impacts of alternative policy options. The guidelines provide information about the processes by which to obtain the necessary knowledge on the impacts of policy initiatives, including processes such as the use of scientific tools and public consultations. These guidelines were revised in 2006 and 2009. In 2006, an IA board was also launched at the highest level of the EC to provide quality support and control under the authority of the EC president. The board examines all of the EC's IAs. Its members are high-level officials from the EC services most directly linked with the three pillars of the IA: economy, society, and environment. The members are appointed on the basis of their expert knowledge (European Commission 2010). The IA board issues opinions on the quality of individual draft IAs and provides advice on methodology to the EC services in the early stages of preparing the IAs. The opinions of the board are not binding. However, the opinion accompanies the draft initiative, together with the IA report, throughout the EC's political decision making. All IAs, including the IA board opinions, are published once the EC has adopted the relevant proposal.

\section{Use of scientific tools}

The IA system is meant to inform and improve policy coherence but not to replace the political process or determine the final decision. IA is conceived as an assessment of distinct alternatives to achieve a specified policy objective, thereby providing the basis for a decision whereby the policy with the best net benefit is chosen (European Commission 2002). Scientific tools such as environmental, socioeconomic, and integrated models can provide ways to structure and explore problems and generate quantitative information for analyzing and characterizing decision spaces. However, there are recognized gaps between the claims made about the usefulness of such tools and their demonstrated utility in policy (e.g., Mcintosh et al. 2005, Jacob et al. 2008). Here, I aim to advance the debate on IA and the relationship with sustainable development by contributing to a richer understanding of current practices, drawing on empirical evidence. To do so, I first summarize how scientific tools such as environmental, socioeconomic, and integrated models have been developed and used to provide a solid foundation for sustainable policy objectives. I then use three evaluation criteria, i.e., relevancy, accuracy, and legitimacy, to present the results of a scoping study that I 
conducted using document analysis and interviews to evaluate the use of tools in current IA practice through the lenses of the users. I discuss the use of scientific tools and the implementation of a system of tools to support decision processes. Finally, I summarize the principal findings and outline some issues requiring further research to improve current practices. The conclusions reflect my personal opinion; they do not entail an official viewpoint of the EC.

\section{METHODS}

I conducted a scoping study during early 2008 to evaluate and compare 15 different practices, including formal IA exercises within the EC and more experimental and novel research policy cases in the sixth and seventh EU framework programs for research (FP6 and FP7 projects). The 15 practices analyzed were selected from two of the EC's web databases. The first database gives an overview of finalized formal IA reports (http://ec.e uropa.eu/governance/impact/ia carried out/ ia carried out en.htm). The second database, called Cordis, gives an overview of the FP6 (http:// cordis.europa.eu/fp6/projects.htm) and FP7 (http:// cordis.europa.eu/fp7/projects en.html). The empirical data consisted of primary documents such as scientific reports, IA reports, and public policy documents, as well as 10 interviews with researchers and policy makers.

The purpose of the scoping study was to compare the actual use of scientific tools. To be in touch with current practice, the selection of cases was biased toward ongoing or just completed cases that had clear indications of the tools used. In addition, the selection was biased toward cases that had strong recognition within the EC and scientific community of the positive contribution of using scientific tools. The empirical evidence therefore does not provide a full picture of IA. However, my aim was to compare the use of scientific tools by researchers and policy makers in the selected cases.

The selected IA exercises and research policy cases were analyzed based on a set of criteria developed specifically for the scoping study (Table 1). The criteria for evaluating the use of IA tools were inspired by the U.S. Environmental Protection Agency (2000) and included: (1) relevancy, i.e., how closely connected or appropriate the EC's IA and novel IA policy cases are to the renewed EU SDS; (2) accuracy, i.e., the correctness of all detail and capability or success in reaching the intended target; and (3) legitimacy, i.e., the extent to which the IA conforms to a given standard, in this case, the EU SDS and EC IA guidelines. Although IA is often linked with sustainable development and better regulation, the criteria focus on sustainable development. Two different user communities were distinguished: policy makers, i.e., the desk officers within the EC service organizations responsible for IA of EU policies; and researchers, who are supposed to provide scientific knowledge supporting IA via theories and methodologies and/ or supporting IA practices via IA methods. The comparative case-study design of the scoping study allowed for in-depth study of the science-policy interface and systematic examination of similarities and differences among the 15 cases.

\section{RESULTS}

The scoping study on the use of IA tools revealed the existence of a variety of successfully established assessment tools linking to several sustainable development challenges. As a concept, the use of IA tools is effectively accepted among researchers and policy makers as an assessment process to support sustainable policy measures. Although its general application is still recent, more and more expertise is being accumulated within the EC and among research projects. In 2008, for example, more than 135 IA exercises were conducted within the EC.

I next present the findings of the scoping study, including empirical evidence from interviews and analyzed documents. The set of criteria and related series of questions ensured a consistent approach to data collection, were analytically sound, and supported a comprehensive dialogue during the interviews. I use the three criteria to present the findings; however, issues often relate directly or indirectly to more than one criterion, and there is some overlap. The main findings reflect on the use of the tools in general. Hence, the criteria should be considered as a framework to support comparison, not as a strict classification. 
Table 1. Overview of the set of criteria and related questions developed to analyze the use of impact assessment tools to support sustainable policy objectives (after EPA 2000).

\begin{tabular}{|c|c|c|}
\hline Criterion & Description & Related questions \\
\hline Relevancy & $\begin{array}{l}\text { How closely connected or } \\
\text { appropriate the European } \\
\text { Commission's impact assessments } \\
\text { (IAs) and novel IA policy cases are } \\
\text { to the renewed EU Sustainable } \\
\text { Development Strategy (SDS). }\end{array}$ & $\begin{array}{l}\text { How pertinent, appropriate, and useful are IA and the use of tools as } \\
\text { aids to policy making, with reference to the EU SDS Strategy? } \\
\text { Does the assessment provide relevant information that corresponds to } \\
\text { the analytical needs of the European Commission? } \\
\text { Is the IA evaluating the social, economic, and environmental } \\
\text { dimensions of sustainable development in a balanced way, taking into } \\
\text { account international dimensions of sustainable development and the } \\
\text { cost of inaction? }\end{array}$ \\
\hline Accuracy & $\begin{array}{l}\text { The quality or state of being exact } \\
\text { or precise and correct in all detail; } \\
\text { of being capable of or successful in } \\
\text { reaching the intended target. }\end{array}$ & $\begin{array}{l}\text { What types of data are being provided? Does the degree of detail fit } \\
\text { with the scope of the IA? How are the data generated and presented? } \\
\text { What types of models are being applied? How recent are they? Are the } \\
\text { models well established within the scientific community and accepted } \\
\text { by the policy makers? } \\
\text { Who has contributed to the IA? }\end{array}$ \\
\hline Legitimacy & $\begin{array}{l}\text { The extent to which the IA } \\
\text { conforms to a given standard (i.e., } \\
\text { the EU SDS and European } \\
\text { Commission's IA guidelines). }\end{array}$ & $\begin{array}{l}\text { How is the IA conceptualized? Does the practice comply with the } \\
\text { European Commission's IA guidelines? Is there a balance between } \\
\text { qualitative and quantitative approaches? Is there external involvement, } \\
\text { from consultants and research institutes, for example? } \\
\text { Who is contributing to the IA? Are stakeholders involved from } \\
\text { different target groups with a broad range of backgrounds? } \\
\text { What type of consultations tools are being employed? }\end{array}$ \\
\hline
\end{tabular}

\section{Relevancy}

Most desk officers recognize the potential relevance of scientific tools to provide evidence for comparing and selecting options to develop sustainable policy objectives. However, they also realize that current IA tools have their limits. The knowledge generated by the tools is biased by the design of the tool, i.e., the theoretical underpinnings and assumptions within the analytical framework, as well as the availability of data to be used within the tool. Also, desk officers find it difficult to evaluate the contributions of current IA tools for sustainable development in the complex process of decision making. Often, researchers find the scope of the current IA exercises too narrow to support real change for unsustainable developments such as climate change and biodiversity loss. However, it is important to acknowledge that the outcomes of IAs and of decisions are not necessarily one and the same (Cashmore 2007). The merit of using IA tools should be evaluated in terms of their support for the decision process. IA is an aid, not a substitute, for political judgment (European Commission 2002).

A variety of analytical tools are used in current IA practice to evaluate the social, economic, and environmental dimensions of sustainable development in a balanced way. For instance, participatory approaches in risk assessment can offer ways to be more rigorous and complete in the mapping of different framings (Stirling and Scoones 2009). Another effectively established tool in Europe is the use of sustainable development indicators (De Smedt 2006). A set of indicators can provide a sound analytical reference to the well-known three pillars and/or the challenges of the renewed EU SDS. Also, indicators can serve as a means to communicate the IA outcomes because of their synthesizing and/or benchmarking abilities. Science has effectively accepted concepts and data for a broad range of economic and environmental indicators. However, some of the social indicators are lacking sound concepts or monitoring initiatives to provide 
qualitative data. Although the use of this indicator list often entails practical problems because of missing data, less appropriate indicators for the policy proposal, and other factors, the indicators can be seen as a checklist to ascertain if the effects of the policy objective on different sustainable development dimensions are reported.

\section{Accuracy}

The EC IA guidelines foresee six analytical steps that support a coherent presentation within the formal IA exercise. In contrast, most of the research projects only report on some of the six analytical steps. The guidelines also recommend the use of quantitative information. Indeed, the scoping study revealed that most of the knowledge generated, analyzed, and presented has a strong quantitative origin, including official statistics and numeric models. Most of the models used were developed by standing research organizations, had been peer reviewed, and had been applied in policy development for many years. In general, most researchers and policy makers perceive the quantitative knowledge as accurate. However, most quantitative knowledge is often fragmented because of sector-specific models, is based strongly on assumptions of the past, and ignores the high levels of uncertainty of such a complex and cross-cutting issue as sustainable development.

Scientific tools are needed, and a broad variety of tools have been developed to improve accuracy. However, the ecological and social sciences have developed their tools independently and, in practice, the different tools do not combine easily (Norgaard 2008). Indeed, most of the tools that address sustainability are based on a set of theories. However, the connection between practice and theory has traditionally been ignored (Gunderson et al. 2007). Following a strict interpretation, there is no evidence of a scientifically sound way to address sustainability fully in its breadth and depth. In practice, there is a great deal of variation in the presentation of evidence in the IA exercises and research projects. This issue partly reflects the complexity of policy making and has been acknowledged in the first EC communication on IA (European Commission 2002). However, better incorporation of this variation is needed in the design of new IA tools to improve accuracy. In particular, the social dimension could benefit from further analytical support (European Commission
2010). Additionally, some researchers are more interested in developing new tools and are less focused on policy relevance. Thus, promising or successful tools, from a policy perspective, are not always being maintained or further applied by the developers to address new policy challenges. These "orphan tools" indicate a potential limit to research funding.

Desk officers and researchers also mention time and resource constraints as affecting the accuracy of IAs. It should be noted that research projects and policy initiatives such as IA exercises have a limited lifespan and have specific start and completion dates, making it difficult to link them. Even more than constraints of data availability and time to perform analyses, the desk officers and researchers recognize that the use of tools depends on the people conducting the assessment. Hence, both user communities recognize the importance of carefully planning the process.

\section{Legitimacy}

Current tools in IA practice do not show an agreed understanding of sustainable development, and the detailed principles required to implement sustainable development are contested profoundly. Most practice, however, does include some reference to the renewed EU SDS and/or some of the seven challenges, providing some form of legitimacy. The seven challenges of the renewed EU SDS are climate change and clean energy; sustainable transport; sustainable production and consumption; better management of natural resources; public health threats; social inclusion, demography, and migration; and fighting global poverty. In particular, the EC IA guidelines and IA board support the legitimacy of an IA exercise and the related decision-making process. The fact that the IA board was launched at the highest level of the EC to provide independent quality support and control also underpins the legitimacy of IA within the EC. Legitimacy within the IA system begins with clear responsibilities for the policy maker, not only to prepare the policy initiative, but also to prepare an integrated assessment of the proposed policy initiatives. Actual practice within research projects is less connected with the formal IA system. As mentioned by the researchers I interviewed, there is no successfully established and accepted theory of sustainability science to support the legitimacy of the current research tools. Most researchers see 
sustainability science as a trans-disciplinary endeavor to understand better the complex dynamic interactions among environmental, social, and economic issues. Some researchers strongly believe that science should go beyond progress in a better understanding of the complex dynamic interactions. The commonly used development statistics such as gross domestic product are still very much focused on progress and may not be capturing some phenomena that have an increasing impact on society. For example, if citizens are concerned about the quality of air, and air pollution is increasing, then statistical measures that ignore air pollution will provide an inaccurate estimate of what is happening to citizens' well-being. Or, a tendency to measure gradual change may be inadequate to capture risks of abrupt alterations in the environment such as climate change (Stiglitz et al. 2009).

Science should also engage in the process of putting knowledge into action, i.e., for a sustainable transition, goals and policy measures must be assessed. This has posed important challenges to the scientific community to provide not only sound theories, but also efficient and reliable assessment tools that better address these needs.

\section{DISCUSSION}

EU policy making is largely based on expertise and involves the handling of complex technical information at various levels. While such an expertbased regulatory policy is seen by some as a guarantee of rational decision making, it is sometimes perceived as technocratic. Achieving more sustainability depends on establishing an interpretation or interpretations of sustainable development in a given context. Policy makers have to rely on information that allows them to judge on a regular basis whether or not the current evolution of development is to be considered as a contribution to stay or engage on a sustainable path. As such, sustainable policies require constant feedback to policy makers to establish a connection between past evolutions and future expectations while integrating the underlying learning-by-doing dynamic (Bauler 2007). This process should reflect on what to avoid, as well as what to seek to attain, including the relevant relationships, interdependencies, and uncertainties (Tabara et al. 2008). It should also encourage enough solidarity among stakeholders to accept joint responsibility (Norton 2005).
Therefore, sustainable development, as a policy domain, poses particular challenges on the agenda of policy makers because of its conceptual vagueness and inherent complexity (O'Riordan 2008) and the uncertainty related to policy choices and their outcomes in a multi-level governance structure such as the EC (Hooghe and Marks 2001). Furthermore, as a research domain, sustainable development is a complex and multi-dimensional phenomenon with a breadth and depth that cannot be covered fully by the current theoretical underpinnings from science (Rotmans 2006). Hence, science should provide better understanding and evidence for policy, and policy makers should increase the transparency of the difficult policy decisions lying ahead (Cashmore 2004, Ruddy and Hilty 2008). To tackle the sustainability challenge, science must also incorporate plurality, i.e., a diversity of disciplines and theories, much more than it has in the past. The practical problem to be addressed is whether it is possible to design and implement a system of tools that operates effectively in complex and pluralistic situations to support a deliberative decision process (Norton 2005).

The scoping study confirms the importance of using sound scientific tools such as sustainable development indicators and quantitative models to strengthen the analytical base of the policy objectives. Indeed, using IA tools can provide researchers and policy makers with a relevant and legitimate assessment and decision support process. The scoping study provides some evidence of effective close, long-term collaboration between researchers and policy makers. The study also confirms that these promising experiments are not just limited to research projects, but can also be found in formal IA experiences within the EC, which is in contrast with previous findings (Weaver and Jordan 2008). This supports the importance of an intensive collaboration whereby researchers and policy makers interact to support a more integrated and explorative approach. An assessment process is often more effective if the knowledge being produced and communicated at the interface between science and policy is perceived by both sides to be credible (meeting scientific standards), legitimate (resulting from a fair process that reflects the interests of stakeholders), and salient (answering questions relevant to potential users; Cash et al. 2003). For example, the newest generation of IA models will be more demand driven, in the sense that policy makers need to be involved at an early 
stage of model development (Rotmans 2006). This is needed because the dialog linking researchers and policy makers will not happen by itself (Liberatore 2001). Gulbrandsen (2008) states that science has a greater chance of guiding (policy) action when combined with an inclusive, deliberative, decisionmaking process.

Based on my findings, the EC's IA system is regarded by both sets of users (researchers and policy makers) as a system of tools that operates effectively in complex and pluralistic situations to support a deliberative decision process within the guiding principle of sustainability. In particular, the combination of successive and complementary policy initiatives within the IA system to enhance the use of scientific tools provides a strong potential to be effective. Radaelli and Meeuwese (2010) acknowledge that the IA system provides strong incentives to policy makers to further improve transparency and the analytical base of the EC's proposals through their own responsibility of drafting IAs and through the challenging of proposals by other colleagues such as other Commission services.

However, both groups that use the IA tools acknowledge that the full potential of the tools has not yet been met. Scientific tools often struggle to bridge the gap between science and the formal policy process (e.g., Mcintosh et al. 2005). This is also observed as the potential gap between the contributions of researchers and the types of assessment tools that policy makers seem most able or willing to use (Lee 2006). In most cases, assessment practice is biased toward economic impacts and administrative costs (Hertin et al. 2009). The tools used in any such process-based application must be simple and based as far as possible on rigorous analysis while recognizing explicitly where value judgments occur (Turnpenny 2008). Moreover, although scientific models are simplifications of reality, many remain so complex that they are seen as black boxes instead of transparent analytical tools. Hence, some of what modelers see to be the great strengths of modeling tools are felt by nonmodelers to be serious weaknesses (Lee 2006, Lotze-Campen 2008). Consequently, research outcomes do not fully reach the policy makers. Of course, the complexity of sustainable development does not entail easy application of research findings. Moreover, research projects have a limited lifespan and therefore do not facilitate easy application (Leeuwis
2004). The scoping study reveals that most of the research outcomes are not specific enough to support direct use in the decision process. Thus, knowledge delivered must be recognized as both factually and politically relevant.

\section{CONCLUSIONS}

My findings indicate that the IA system in the EC is regarded by researchers and policy makers as a system of tools that operates effectively to support a deliberative decision-making process within the guiding principle of sustainability. In particular, the combination of various successive and complementary initiatives to enhance the use of scientific tools provides a strong potential for effectiveness. However, the existing tools are biased toward economic and environmental models, and there is still a potential gap between the contributions of researchers and the types of assessment tools that policy makers seem most able or willing to use. Consequently, research outcomes do not fully reach the policy makers. Specific initiatives are needed to shape the collaboration between science and policy. Further initiatives on IA tools should therefore include a joint collaboration between researchers and policy makers to develop a shared understanding of what constitutes a satisfactory assessment, i.e., relevant, accurate, and legitimate, using the appropriate combination of scientific tools. To be effective, such initiatives should include a dialog between the two communities of practice during the phase of formulating the research agenda on IA tools. If collaboration between researchers and policy makers evolves in such a way, using IA tools can be considered a frontline practice connecting science and policy in making sustainable development operational.

Responses to this article can be read online at: http://www.ecologyandsociety.org/voll5/iss4/art30/ responses/

\section{Acknowledgments:}

I am grateful to Anya Jones, Serge Stalpers, J. David Tàbara, and Katharina Helming for their constructive comments on the preliminary results of the scoping study. The constructive comments of the reviewers were very helpful to better focus and 
shape this paper. This publication was funded under the EU Sixth Framework Programme for Research, Technological Development, and Demonstration, Priority 1.1.6.3, Global Change and Ecosystems (European Commission, DG Research, contract 003874 (GOCE)). Its content does not represent the official position of the European Commission and is entirely the responsibility of the author.

\section{LITERATURE CITED}

Adelle, C., J. Hertin, and A. Jordan. 2006. Sustainable development 'outside' the European Union: what role for impact assessment? European Environment 16(2):57-72.

Bauler, T. 2007. Indicators for sustainable development: a discussion of their usability. Dissertation. Université Libre de Bruxelles, Brussels, Belgium. [online] URL: http://theses.ulb. ac.be/ETD-db/collection/available/ULBetd-051020 07-104144/.

Cash, D. W., W. C. Clark, F. Alcock, N. M. Dickson, N. Eckley, D. H. Guston, J. Jäger, and R. B. Mitchell. 2003. Knowledge systems for sustainable development. Proceedings of the National Academy of Sciences 100(14):8086-8091.

Cashmore, M. 2004. The role of science in environmental impact assessment: process and procedure versus purpose in the development of theory. Environmental Impact Assessment Review 24(4):403-426.

Cashmore, M. 2007. The contribution of environmental assessment to sustainable development: toward a richer conceptual understanding. Pages 106-130 in C. George and C. Kirkpatrick, editors. Impact assessment and sustainable development: European practice and experience. Edward Elgar, Cheltenham, UK.

Council of the European Union. 2006a. Renewed EU sustainable development strategy. Document 10117/06. Council of the European Union, Brussels, Belgium. [online] URL: http://register.consilium.eu ropa.eu/pdf/en/06/st10/st10117.en06.pdf.
Council of the European Union. 2006b. Decision No. 1982/2006/EC of the European Parliament and of the Council of 18 December 2006 concerning the Seventh Framework Programme of the European Community for research, technological development and demonstration activities (2007-2013). Document $\operatorname{COM}(2006) 364$ final. Council of the European Union, Brussels, Belgium. [online] URL: http://eurlex.europa.eu/LexUriServ/LexUriServ.do?uri=OJ: L:2006:412:0001:0041:EN:PDF.

De Smedt, P. 2006. Asking the right questions: new approaches on measuring sustainable development. Working paper 14 of the second meeting. Joint UNECE/OECD/Eurostat Working Group on Statistics for Sustainable Development, Oslo, Norway. [online] URL: http://www.unece.org/stats/ documents/2006/11/sust-dev/wp.14.e.pdf.

European Commission. 2002. Communication from the Commission on Impact Assessment. Document $\operatorname{COM}(2002) 276$ final. European Commission, Brussels, Belgium. [online] URL: htt p://eur-lex.europa.eu/LexUriServ/LexUriServ.do?uri= COM:2002:0276:FIN:EN:PDF.

European Commission. 2010. Impact Assessment Board Report for 2009. Document SEC(2009) 1728 final. European Commission, Brussels, Belgium.

Gulbrandsen, L. H. 2008. The role of science in environmental governance: competing knowledge producers in Swedish and Norwegian forestry. Global Environmental Politics 8(2):99-122.

Gunderson, L., C. Folke, and M. A. Janssen. 2007. Reflective practice. Ecology and Society 12 (2): 40. [online] URL: http://www.ecologyandsociety. org/vol12/iss2/art40/.

Hertin, J., J. Turnpenny, A. Jordan, M. Nilsson, D. Russel, and B. Nykvist. 2009. Rationalising the policy mess? Ex ante policy assessment and the utilisation of knowledge in the policy process. Environment and Planning A 41(5):1185-1200.

Hooghe, L., and G. Marks. 2001. Multi-level governance and European integration. Rowman \& Littlefield, Oxford, UK.

Jacob, K., J. Hertin, P. Hjerp, C. Radaelli, A. Meuwese, O. Wolf, C. Pacchi, and K. Rennings. 
2008. Improving the practice of impact assessment: policy conclusions from FP6 EVIA project. EVIAPolicy Paper. Forschungszentrum für Umweltpolitik, Berlin. [online] URL: http://userpage.fu-berlin.de/ffu/ evia/EVIA Policy Paper.pdf.

Lee, N. 2006. Bridging the gap between theory and practice in integrated assessment. Environmental Impact Assessment Review 26(1):57-78.

Lee, N., and C. Kirkpatrick. 2006. Evidencebased policy-making in Europe: an evaluation of European Commission integrated impact assessments. Impact Assessment and Project Appraisal 24 (1):23-33.

Leeuwis, C. 2004. Fields of conflict and castles in the air. Some thoughts and observations on the role of communication in public sphere innovation processes. Journal of Agricultural Education and Extension 10(2):63-76.

Liberatore, A. 2001. From science/policy interface to science/policy/society dialogue. Pages 117-128 in Organisation for Economic Co-operation and Development, editor. Social sciences for knowledge and decision making. Organisation for Economic Co-operation and Development, Paris, France.

Lotze-Campen, H. 2008. The role of modelling tools in integrated sustainability assessment (ISA). International Journal of Innovation and Sustainable Development 3(1-2):70-92.

Mcintosh, B. S., P. Jeffrey, M. Lemon, and N. Winder. 2005. On the design of computer-based models for integrated environmental science. Environmental Management 35(6):741-752.

Norgaard, R. B. 2008. Finding hope in the Millennium Ecosystem Assessment. Conservation Biology 22(4):862-869.

Norton, B. G. 2005. Sustainability: a philosophy of adaptive ecosystem management. University of Chicago Press, Chicago, Illinois, USA.

O'Riordan, T. 2008. Some reflections on the conditions for favouring Integrated Sustainability Assessments. International Journal of Innovation and Sustainable Development 3(1-2):153-162.

Radaelli, C. M., and A. C. M. Meuwese. 2010. Hard questions, hard solutions: proceduralisation through impact assessment in the EU. West European Politics 33(1):136-153.

Rotmans, J. 2006. Tools for integrated sustainability assessment: a two-track approach. Integrated Assessment Journal 6(4):35-57.

Ruddy, T. F., and L. M. Hilty. 2008. Impact assessment and policy learning in the European Commission. Environmental Impact Assessment Review 28(2-3):90-105.

Stiglitz, J. E., A. Sen, and J.-P. Fitoussi. 2009. Report by the Commission on the Measurement of Economic Performance and Social Progress. European Commission, Brussels, Belgium. [online] URL: http://www.stiglitz-sen-fitoussi.fr/documents/ rapport anglais.pdf.

Stirling, A. C., and I. Scoones. 2009. From risk assessment to knowledge mapping: science, precaution, and participation in disease ecology. Ecology and Society 14(2): 14. [online] URL: http: //www.ecologyandsociety.org/vol14/iss2/art14/.

Tabara, J. D., E. Roca, C. Madrid, P. Valkering, P. Wallman, and P. M. Weaver. 2008. Integrated sustainability assessment of water systems: lessons from the Ebro River basin. International Journal of Innovation and Sustainable Development $\mathbf{3}$ (1-2):48-69.

Turnpenny, J. 2008. "Are we nearly there yet?" Lessons for integrated sustainability assessment from EU environmental policy-making. International Journal of Innovation and Sustainable Development 3(1-2):33-47.

U.S. Environmental Protection Agency. 2000. Projecting land-use change: a summary of models for assessing the effects of community growth and change on land-use patterns. EPA/600/R-00/098. U.S. Environmental Protection Agency, Cincinnati, OH, USA. [online] URL: http://knowledge.fhwa.dot. gov/ReNEPA/ReNepa.nsf/docs/5558AAFBF4A78 F5285256FDC005E50A3?opendocument\&Group= Cumulative\%20and\%20Indirect\%20Impacts \&tab= REFERENCE.

Weaver, P. M., and A. Jordan. 2008. What roles are there for sustainability assessment in the policy process? International Journal of Innovation and Sustainable Development 3(1-2):9-32. 